\title{
Desenvolvimento numa perspectiva keynesiana: uma resposta ao Professor Fernando Holanda Barbosa
}

José Luis Oreiro*

O instigante artigo do Professor Fernando de Holanda Barbosa publicado neste número do boletim Economia \& Tecnologia tem o indiscutível mérito de deslocar o debate econômico da análise da conjuntura econômica de curto-prazo para os determinantes da tendência de crescimento de longo-prazo. Com efeito, como certa vez destacou Robert Lucas, não há nada mais importante do ponto de vista do bem-estar material de uma sociedade do que o crescimento econômico. De fato, pequenas diferenças entre as taxas anuais de crescimento do produto real entre os países, quando acumuladas ao longo de vários anos, geram diferenças significativas nos níveis de renda per capita. A validade dessa afirmação pode ser constatada por intermédio da análise da tabela 1 , na qual reproduzimos a performance de crescimento de um grupo de países selecionados ao longo dos últimos 130 anos. Os dados da Tabela 1 mostram claramente que alguns países que possuíam o mesmo nível de renda per capita no final do século XIX - por exemplo, Argentina e Canadá - chegaram ao final do século XX com níveis de renda per capita totalmente diferentes em virtude dos diferenciais entre as taxas de crescimento da renda per capita durante o século XX.

Tabela 1. Crescimento da renda per capita de países selecionados

\begin{tabular}{lcccc}
\multicolumn{1}{c}{ País } & Período & $\begin{array}{c}\text { PIB per capita } \\
\text { inicial (US\$ de 1985) }\end{array}$ & $\begin{array}{c}\text { PIB per capita } \\
\text { final (US } \$ \text { de 1985) }\end{array}$ & $\begin{array}{c}\text { Taxa média de } \\
\text { crescimento }\end{array}$ \\
\hline Japão & $1890-1990$ & 842 & 16.144 & 3,00 \\
Brasil & $1900-1987$ & 436 & 3.417 & 2,39 \\
Canadá & $1870-1990$ & 1.330 & 17.070 & 2,15 \\
Alemanha & $1870-1990$ & 1.223 & 14.288 & 2,07 \\
EUA & $1870-1990$ & 2.244 & 18.258 & 1,76 \\
China & $1900-1987$ & 401 & 1.748 & 1,71 \\
México & $1900-1987$ & 649 & 2.667 & 1,64 \\
Reino Unido & $1870-1990$ & 2.693 & 13.589 & 1,36 \\
Argentina & $1900-1987$ & 1.284 & 3.302 & 1,09 \\
Indonésia & $1900-1987$ & 499 & 1.200 & 1,01 \\
Paquistão & $1900-1987$ & 413 & 885 & 0,88 \\
Índia & $1900-1987$ & 378 & 662 & 0,65 \\
Bangladesh & $1900-1987$ & 349 & 375 & 0,08 \\
\hline
\end{tabular}

Fonte: Robert Barro e Xavier Sala - I-Martin, Economic Growth. Nova Iorque. McGraw-Hill 1995.

\footnotetext{
* Professor do Departamento de Economia da Universidade Federal do Paraná (UFPR). Diretor do Centro de Pesquisas Econômicas (CEPEC/UFPR). Pesquisador do CNPq. Endereço eletrônico: joreiro@ufpr.br. Página pessoal: http://www.joseluisoreiro.ecn.br
} 
Sendo assim, a questão fundamental a ser respondida é: o que determina o crescimento econômico de longo-prazo? Podemos dizer que essa pergunta é a questão mais importante na agenda de pesquisa dos economistas desde a fundação da Ciência Econômica por Adam Smith, na segunda metade do século XVIII. De fato, o livro que entrou para a História do Pensamento Econômico como a obra fundadora da economia como ciência denominavase "Uma Investigação sobre a Origem e as Causas da Riqueza das Nações" de Adam Smith.

Nesse contexto, o artigo do Professor Fernando de Holanda Barbosa apresenta o crescimento de longo-prazo numa perspectiva neoclássica, segundo a qual os limites ao desenvolvimento econômico são postos pelo lado da oferta da economia. Mais precisamente, o crescimento de longo-prazo é limitado/ determinado pelo ritmo de expansão dos estoques de fatores de produção em conjunto com o ritmo, exogenamente determinado, de progresso tecnológico. Dessa forma, a taxa de crescimento de longo-prazo da economia é determinada, por intermédio de uma análise de growth accounting, pela soma entre a taxa de crescimento do estoque de capital (ponderada pela participação dos ganhos de capital na renda nacional), pela taxa de crescimento da força de trabalho (ponderada pela participação dos salários na renda nacional) e pela taxa de crescimento da produtividade total dos fatores de produção, uma medida do ritmo de progresso tecnológico da economia. Segundo as estimativas do Professor Barbosa, a economia brasileira poderia crescer, de forma sustentável no longo-prazo, a um ritmo de $3,5 \%$ ao ano.

No presente artigo irei fazer dois tipos de críticas a análise do Professor Barbosa: em primeiro lugar irei argumentar que, tomando como dado o instrumental neoclássico de growth accounting utilizado pelo Professor Barbosa, as estimativas por ele apresentadas a respeito da taxa potencial de crescimento da economia brasileira estão superdimensionadas. Em segundo lugar, irei argumentar que existem boas razões, a nível teórico e empírico, para questionar a validade de um modelo de crescimento no qual a disponibilidade dos fatores de produção seja o entrave fundamental ao desenvolvimento econômico.

A fórmula apresentada pelo Professor Barbosa foi originalmente desenvolvida por Robert Solow num artigo publicado em 1957. Nesse artigo, Solow tenta quantificar a contribuição da acumulação de capital para o crescimento da economia americana na primeira metade do século XX. Para tanto, Solow supõe a existência de uma função macroeconômica de produção na qual a quantidade produzida num dado período de tempo é uma função da quantidade empregada de capital e de trabalho, de tal forma que $Q=A . f(K, L)$, onde $\mathrm{Q}$ é a quantidade produzida de bens e serviços, $\mathrm{K}$ é a quantidade empregada de capital, L é a 10 
quantidade empregada de trabalho e A é uma variável que representa o "estado das artes" da economia, ou seja, o nível tecnológico existente na economia num dado ponto do tempo. A função $f($.) é suposta ser homogênea linear, ou seja, os retornos de escala são tidos como constantes. Por fim, prevalece a concorrência perfeita em todos os mercados, de tal forma que cada fator de produção é remunerado com base na sua produtividade marginal. Daqui se segue que - com base no teorema de Euller-Wicksteed - toda a renda gerada na economia é integralmente gasta na remuneração dos fatores de produção com base em suas produtividades marginais. Não sobra nada da renda agregada para remunerar o esforço de pesquisa e desenvolvimento de novas tecnologias. Nesse contexto, o progresso tecnológico só pode ser tratado como exógeno ao sistema econômico.

Aqui nos defrontamos com a primeira grande dificuldade de qualquer análise do tipo growth accounting, a saber: como medir a contribuição do progresso tecnológico para o crescimento de longo-prazo num contexto na qual a teoria utilizada para explicar esse crescimento diz que não há nenhuma explicação econômica para o progresso tecnológico? No artigo de 1957, Solow contorna esse problema ao tornar a produtividade total dos fatores de produção - ou seja, a taxa de crescimento de A na fórmula apresentada acima - uma variável puramente residual, determinada pela diferença entre a taxa efetiva de crescimento (anual) do produto real e o crescimento do produto real que poderia ser explicado pela acumulação dos fatores de produção, isto é, pela soma da taxa de crescimento do estoque de capital (ponderado pela participação do capital na renda nacional) e pela taxa de crescimento da força de trabalho (ponderado pela participação dos salários na renda nacional). Em outras palavras, o "progresso tecnológico" nos modelos de crescimento a la Solow é tão simplesmente uma "medida da nossa ignorância", ou seja, aquela parte do crescimento de longo-prazo que não conseguimos explicar por intermédio da acumulação dos fatores de produção. Em tempo: Solow estimou que cerca de $7 / 8$ do crescimento da economia norte-americana na primeira metade do século XX não poderia ser explicado pelo crescimento dos estoques de capital e trabalho. Em outras palavras, $7 / 8$ do crescimento da economia norte-americana da primeira metade do século XX não tem explicação com base na teoria econômica neoclássica!

Daqui se segue que existem sérias dúvidas metodológicas sobre a validade da fórmula de Solow como base para se estimar o crescimento de longo-prazo. $\mathrm{Na}$ verdade poderíamos somar a essas dúvidas outros questionamentos advindos do debate que ficou conhecido como a "Controvérsia do Capital". Com efeito, durante a década de 1950, Joan Robinson e Piero Sraffa levantaram sérios questionamentos a respeito da metodologia utilizada pela teoria 
neoclássica para mensurar o estoque de capital. O argumento fundamental de Robinson e Sraffa é que o valor do estoque de capital não é independente da distribuição funcional da renda entre salários e lucros, de tal forma que não é possível calcular o valor e/ou a taxa de crescimento do estoque de capital de forma independente da participação do capital na renda nacional. Em outras palavras, não existe nenhuma forma metodologicamente aceitável de se separar a taxa de crescimento do estoque de capital da participação dos lucros na renda. Nesse contexto, a fórmula de Solow simplesmente não pode ser aplicada em função da incapacidade de se calcular a contribuição do capital para o crescimento econômico de longo prazo.

Mesmo que façamos "vista grossa" a todos esses problemas metodológicos - que são gravíssimos - as estimativas do Professor Barbosa ainda são excessivamente otimistas. Com efeito, nos últimos 25 anos a taxa média de crescimento do produto real tem se situado em torno de $2,7 \%$ ao ano, ou seja, quase 1 ponto percentual abaixo da estimativa por ele utilizada. Erros dessa magnitude podem ser desprezíveis para uma análise de médio prazo - 5 a 10 anos - mas geram estimativas completamente erradas sobre o comportamento da renda per capita quando consideramos o intervalo de tempo relevante para a teoria do crescimento econômico, ou seja, entre 50 a 70 anos.

O "viés otimista" da análise do Professor Barbosa se deve à estimativa por ele utilizada para a relação capital-produto. Com efeito, o Professor Barbosa supõe que a quantidade de capital tecnicamente necessária para produzir uma unidade de produto situa-se em torno de 2,7\%. Num artigo publicado no número anterior do boletim Economia \& Tecnologia, eu havia estimado o valor desse coeficiente em torno de 3,2\%, baseando-me nos dados do Ipeadata a respeito da série do valor do estoque de capital da economia brasileira. Dessa forma, utilizando os demais parâmetros utilizados pelo Professor Barbosa, a taxa estimada de crescimento do estoque de capital cai de $4 \%$ para cerca de $2,75 \%$ ao ano. Nessas condições, supondo válidos os demais parâmetros, a estimativa de crescimento potencial se reduz de 3,5\% ao ano para 3\% ao ano, um valor bem mais próximo do valor realmente observado no Brasil nos últimos 25 anos.

Irei agora me voltar para uma crítica externa ao modelo de crescimento utilizado pelo Professor Barbosa. Os modelos de crescimento neoclássicos supõem que o limite fundamental ao crescimento de longo prazo é a disponibilidade de fatores de produção. A demanda agregada é relevante apenas para explicar o grau de utilização da capacidade produtiva, mas não tem nenhum impacto direto na determinação do ritmo de expansão da capacidade produtiva. No longo prazo vale a "Lei de Say", ou seja, a oferta (disponibilidade 
de fatores de produção) determina a demanda agregada. Mas será verdade que a disponibilidade de fatores de produção é independente da demanda? Comecemos com a disponibilidade de capital: a quantidade existente de capital num dado ponto do tempo - ou melhor, a capacidade produtiva existente na economia - é resultante das decisões passadas de investimento em capital fixo. Daqui se segue que o estoque de capital não é uma constante determinada pela "natureza", mas depende do ritmo no qual os empresários desejam expandir o estoque de capital existente na economia.

Dessa forma, o condicionante fundamental do "estoque de capital" é a decisão de investimento. O investimento, por sua vez, depende de dois conjuntos de fatores: i) o custo de oportunidade do capital (largamente influenciado pela taxa básica de juros controlada pelo Bacen); ii) as expectativas a respeito do crescimento futuro da demanda por bens e serviços.

Nesse contexto, se os empresários anteciparem um crescimento firme da demanda pelos bens e serviços produzidos pelas suas empresas - como é de se esperar no caso de uma economia que esteja apresentando um crescimento forte e sustentável ao longo do tempo então, eles irão realizar grandes investimentos na ampliação da capacidade de produção. Em outras palavras, o investimento se ajusta ao crescimento esperado da demanda, desde que seja atendida uma restrição fundamental, a saber: a taxa esperada de retorno do capital seja maior do que o custo do capital. Sendo assim, atendida a condição acima referida, a "disponibilidade de capital" não pode ser vista como um entrave ao crescimento de longo prazo. É verdade que no curto e médio prazo a produção não pode aumentar além do permitido pela capacidade física de produção da economia. No longo prazo, contudo, a capacidade de produção pode ser ampliada - por intermédio do investimento em capital físico - de forma a atender a demanda agregada por bens e serviços.

Uma objeção trivial a essa argumentação é que o investimento depende para a sua realização de "poupança prévia", ou seja, qualquer aumento dos gastos de investimento requer que, previamente a realização dos mesmos, haja um aumento da taxa de poupança da economia. Nesse contexto, argumentariam os economistas neoclássicos, a "disponibilidade de capital" se acha limitada pela fração da renda que uma determinada sociedade está disposta a não consumir. A poupança assim definida é determinada pela poupança privada (famílias e empresas), pela poupança do governo e pela poupança externa. No caso brasileiro, o grande entrave ao aumento do investimento seria a insuficiência de poupança do governo.

Não é verdade que o investimento necessite de poupança prévia. Com efeito, a realização dos gastos de investimento exige tão somente a criação de liquidez por parte do 
sistema financeiro. Se os bancos estiverem dispostos a estender as suas linhas de crédito ainda que de curta maturidade - em condições favoráveis; então será possível que as empresas iniciem a implementação dos seus projetos de investimento, encomendando máquinas e equipamentos junto aos produtores de bens de capital. Uma vez realizado o gasto de investimento, será criada uma renda agregada de tal magnitude que, ao final do processo, a poupança agregada irá se ajustar ao novo valor do investimento em capital físico. A poupança, assim criada, poderá então ser utilizada para o funding das dívidas de curto prazo das empresas junto aos bancos comerciais, ou seja, as empresas poderão - por intermédio de lucros retidos, venda de ações ou colocação de títulos no mercado - "liquidar" as dívidas contraídas junto aos bancos comerciais no momento em que precisavam de liquidez para implementar os seus projetos de investimento. A poupança se ajusta sempre, e de alguma maneira, ao nível de investimento desejado pelos empresários.

Os entraves à expansão da capacidade produtiva são de natureza financeira, mais especificamente, referem-se ao custo de oportunidade do capital. As empresas estarão dispostas a ajustar o tamanho de sua capacidade produtiva ao crescimento previsto da demanda desde que a taxa esperada de retorno dos novos projetos de investimento seja superior ao custo de oportunidade do capital. Grosso modo, podemos definir o custo do capital como sendo igual à taxa média de juros que a empresa tem que pagar pelos fundos requeridos pelo financiamento dos seus projetos de investimento. Existem três fontes de fundos para o financiamento dos projetos de investimento, a saber: lucros retidos, endividamento e emissão de ações. Dessa forma, o custo do capital é uma média do custo de cada uma dessas fontes de financiamento ponderada pela participação da mesma no passivo total da empresa.

No Brasil, o custo do capital é elevadíssimo, entre outros motivos, porque o custo do financiamento por intermédio da emissão de dívidas é muito alto. Isso se deve a duas razões fundamentais, a saber: i) a taxa básica de juros Selic - que é a taxa pela qual os bancos podem captar recursos via emissão de CDB's - é extremamente alta tanto em termos nominais como em termos reais; e ii) o spread bancário, definido como a diferença entre a taxa de juros pela qual os bancos concedem empréstimos e a taxa pela qual os mesmos conseguem financiar as suas posições, também é muito elevado. Nesse contexto, o elevado custo do financiamento por intermédio de capital de terceiros faz com que o custo do capital acabe por superar qualquer expectativa minimamente plausível sobre o retorno do capital. Dessa forma, poucos projetos de investimento são implementados, reduzindo assim o ritmo de expansão da 
capacidade produtiva. Nos (poucos) momentos nos quais o crescimento da demanda agregada supera o ritmo de expansão da capacidade produtiva - devido, por exemplo, ao aumento da disponibilidade de crédito aos consumidores - acabam ocorrendo pressões inflacionárias que levam o Banco Central do Brasil (BCB) a aumentar a taxa básica de juros, contribuindo assim para manter o custo do capital num patamar superior a rentabilidade esperada dos novos projetos de investimento e impedindo a eliminação das pressões inflacionárias por intermédio de um aumento do ritmo de expansão da capacidade produtiva. Daqui se segue, portanto, que a política monetária adotada pelo BCB é um forte entrave ao crescimento econômico de longo prazo no Brasil.

O que dizer sobre a disponibilidade de trabalho? Será que a quantidade de trabalho pode ser vista como um obstáculo ao crescimento da produção no longo prazo? Dificilmente a disponibilidade de trabalhadores pode ser vista como um obstáculo ao crescimento. Isso por uma série de razões. Em primeiro lugar, o número de horas trabalhadas, dentro de certos limites, pode aumentar rapidamente como resposta a um aumento do nível de produção. No caso brasileiro, por exemplo, a produção da indústria pode aumentar em aproximadamente 44\% - segundo estimativas do IEDI (Valor Econômico, 24/03/2006) - com relação ao nível atual de produção por intermédio do aumento das horas extras trabalhadas. Se considerarmos a possibilidade de adoção de turnos adicionais de trabalho, a produção pode aumentar em cerca de 57\% com respeito ao nível atual de produção.

Em segundo lugar, a taxa de participação - definida como o percentual da população economicamente ativa que faz parte da força de trabalho - pode aumentar como resposta a um forte acréscimo da demanda de trabalho. Com efeito, nos períodos nos quais a economia cresce rapidamente, o custo de oportunidade do lazer - medido pela renda "perdida" pelo indivíduo que "escolhe" não trabalhar (jovens, mulheres casadas e aposentados) - tende a ser muito elevado, induzindo um forte crescimento da taxa de participação. Nesse contexto, a taxa de crescimento da força de trabalho pode se acelerar em virtude do ingresso de indivíduos que, nos períodos anteriores, haviam decidido permanecer fora da força de trabalho. Por fim, devemos ressaltar que a população e a força de trabalho não são um dado do ponto de vista da economia nacional. Isso porque uma eventual escassez de força de trabalho - mesmo que seja de força de trabalho qualificada - pode ser sanada por intermédio da imigração de trabalhadores de países estrangeiros. Por exemplo, países como a Alemanha e a França puderam sustentar elevadas taxas de crescimento durante os anos 1950 e 1960 com a 
imigração de trabalhadores da periferia da Europa (Espanha, Portugal, Grécia, Turquia e Sul da Itália).

O último elemento a ser considerado é o progresso tecnológico. Será que o ritmo de "inovatividade" da economia pode ser considerado como uma restrição ao crescimento de longo prazo? Se considerarmos o progresso tecnológico como exógeno, então certamente o crescimento será limitado pelo ritmo no qual a tecnologia é expandida. Contudo, o progresso tecnológico não é exógeno ao sistema econômico. Em primeiro lugar, o ritmo de introdução de inovações por parte das empresas é, em larga medida, determinado pelo ritmo de acumulação de capital; haja vista que a maior parte das inovações tecnológicas é "incorporada" nas máquinas e equipamentos recentemente produzidos. Dessa forma, uma aceleração da taxa de acumulação de capital - induzida, por exemplo, por uma perspectiva mais favorável de crescimento da demanda - induz um maior ritmo de progresso tecnológico e, portanto, de crescimento da produtividade do trabalho.

Em segundo lugar, aquela parcela "desincorporada" do progresso tecnológico é causada por "economias dinâmicas de escala" como o learning-by-doing. Dessa forma, se estabelece uma relação estrutural entre a taxa de crescimento da produtividade do trabalho e a taxa de crescimento da produção, a qual é conhecida na literatura econômica como "Lei de Kaldor-Verdoon”. Nesse contexto, um aumento da demanda agregada, ao induzir uma aceleração da taxa de crescimento da produção, acaba por acelerar o ritmo de crescimento da produtividade do trabalho. Não é por outra razão que se constata que no Brasil (como em outros países) a taxa de crescimento da produtividade do trabalho tende a cair nos períodos em que a taxa de crescimento da economia se desacelera.

Se a disponibilidade de fatores de produção não pode ser vista como uma restrição ao crescimento econômico no longo prazo, então quais são os fatores que limitam o crescimento? Existem dois elementos que podem limitar o crescimento da produção no longo prazo, a saber: a demanda agregada e as condições de financiamento ao investimento produtivo (das quais já falamos anteriormente).

No longo prazo o determinante último da produção é a demanda agregada. Se houver demanda, as firmas irão responder por intermédio de um aumento da produção e da capacidade produtiva, desde que sejam respeitadas duas condições : i) a margem de lucro seja suficientemente alta para proporcionar aos empresários a taxa desejada de retorno sobre o capital; ii) a taxa realizada de lucro seja maior do que o custo do capital. Nessas condições, a taxa de crescimento do produto real será determinada pela taxa de crescimento da demanda 
agregada autônoma, ou seja, pelo crescimento daquela parcela da demanda agregada que é, em larga medida, independente do nível e/ou da variação da renda e da produção agregada. Em economias abertas, os componentes autônomos da demanda agregada são dois, a saber: as exportações e os gastos do governo. Nesse contexto, a taxa de crescimento de longo prazo será uma média ponderada entre a taxa de crescimento das exportações e a taxa de crescimento dos gastos do governo.

Está claro que no caso brasileiro não é possível "puxar" o processo de crescimento econômico pelo crescimento dos gastos do governo. Isso devido a crise fiscal do Estado brasileiro consubstanciada pela combinação perversa entre elevada dívida pública como proporção do PIB e elevada carga tributária. Nesse contexto, uma elevação da taxa de crescimento dos gastos do governo - sem a necessária contra-partida de um aumento da taxa de crescimento das exportações - geraria um aumento do déficit nominal do setor público, causando uma elevação da dívida pública como proporção do PIB, a qual, em algum momento, se tornaria impagável, obrigando assim ao governo brasileiro a realizar o default de sua dívida interna. Mantido o compromisso com a responsabilidade fiscal, o respeito aos contratos juridicamente perfeitos e, portanto, o respeito à propriedade privada dos meios de produção; a única alternativa disponível ao Brasil é "puxar" o crescimento da demanda agregada por intermédio de uma expansão forte e contínua das exportações.

É neste ponto que as experiências do Brasil e da Coréia do Sul são marcadamente distintas. Enquanto a Coréia se voltou para um modelo de crescimento claramente do tipo export-led já no início dos anos 1950; o Brasil optou por um modelo autárquico de substituição de importações. Com efeito, como ressalta Bresser-Pereira (2004, p.175), o coeficiente de importações (importações/renda) se reduziu de 22\% em 1920 para cerca de 7\% no início dos anos 1960. Embora a substituição de importações fosse necessária e desejável nos estágios iniciais do processo de industrialização do Brasil (fase durante a qual se implantam as indústrias leves de bens de consumo de massa); a continuidade do processo de industrialização durante a década de 1960 exigia a implantação de indústrias pesadas de bens de capital e de bens de consumo de luxo, elevando assim a relação capital-produto e, dessa forma, diminuindo a participação dos salários na renda, o que dificultava o crescimento da demanda agregada doméstica. Em face dessa restrição de demanda, havia duas alternativas possíveis para a continuidade do processo de desenvolvimento brasileiro: ou o Brasil adotava o modelo de export led-growth, estimulando assim o crescimento sustentado das exportações; ou continuava o seu "modelo autárquico" por intermédio do crescimento da demanda por bens 
de consumo de luxo (automóveis, eletrodomésticos e etc.) e, para tanto, deveria promover uma agressiva redistribuição de renda dos segmentos mais pobres da população em direção a classe média, o que poderia ser feito por intermédio de uma política deliberada de "arrocho salarial”. Esta foi à opção adotada pelo Brasil durante o governo militar (Bresser-Pereira, 2004, p.179). O resultado desse processo foi uma nítida piora na distribuição de renda acompanhada de um adiamento do "velho problema" da demanda agregada, como pode ser observado na tabela abaixo.

Tabela 2. Distribuição da renda da população economicamente ativa no Brasil

\begin{tabular}{l|c|c|c|c|c}
\hline \multicolumn{1}{c}{ Distribuição } & 1960 & 1970 & 1972 & 1976 & 1980 \\
\hline $20 \%$ mais pobres & 3,9 & 3,4 & 2,2 & 3,2 & 2,8 \\
$50 \%$ mais pobres & 17,4 & 14,9 & 11,3 & 13,5 & 12,6 \\
$10 \%$ mais ricos & 39,6 & 46,7 & 52,6 & 50,4 & 50,9 \\
$5 \%$ mais ricos & 28,3 & 34,1 & 39,8 & 37,9 & 37,9 \\
$1 \%$ mais ricos & 11,9 & 14,7 & 19,1 & 17,4 & 16,9 \\
\hline
\end{tabular}

Fonte: Bresser-Pereira (2004, p.198).

Nesse contexto, a retomada do crescimento sustentado da economia brasileira só será possível por intermédio de uma política deliberada de promoção das exportações. Para que isso aconteça, no entanto, duas condições devem ser atendidas: em primeiro lugar, a economia brasileira deve mudar a sua pauta de exportações em direção a produtos que possuam uma alta elasticidade-renda da demanda. Dessa forma, o Brasil poderá aumentar a sua taxa de crescimento compatível com o equilíbrio de longo prazo do balanço de pagamentos, nos moldes previstos pelos modelos de crescimento a la Thirwall (2002). Em segundo lugar, a taxa de câmbio real deve permanecer em patamares competitivos de forma a garantir a lucratividade de médio e longo prazo das exportações. É aqui que a política econômica adotada pelo governo Lula é um entrave para o crescimento de longo prazo da economia brasileira. O elevado patamar da taxa de juros tem estimulado uma forte apreciação da taxa nominal e real de câmbio, corroendo de forma sistemática a rentabilidade das exportações. Dessa forma, um crescimento forte e sustentado das exportações não é possível e, sem o mesmo, a economia brasileira não poderá crescer de forma robusta no longo prazo.

\section{Referências Bibliográficas}

BARRO, R.; SALA-I-MARTIN, X. (1995). Economic Growth. Nova Iorque: McGraw-Hill. BRESSER-PEREIRA, L.C. (2004). Desenvolvimento e Crise no Brasil. São Paulo: Editora 34. SOLOW, R. (1957). Technical Change and the Aggregate Production Function. Review of Economics and Statistics, Vol. 39.

THIRLWALL, A. (2002). The Nature of Economic Growth. Edward Elgar: Aldershot. 